\title{
Emprego de reatores anaeróbios em escala real e lagoas de polimento para remoção de ovos de Ascaris suum de efluente de suinocultura
}

\section{Employment of anaerobic reactors in real scale and polishing ponds for removal of eggs Ascaris suum of swine effluent}

\author{
Ana Cristina Araujo Pinto ${ }^{1}$; Luciano dos Santos Rodrigues ${ }^{2 *}$; Israel José da Silva ${ }^{2}$; \\ Adriana Molina Zerbine ${ }^{1}$; Ludmila Alves Rodrigues ${ }^{3}$
}

Resumo

\begin{abstract}
Os confinamentos de suínos e a disposição inadequada desses dejetos trazem como consequência a contaminação de águas e do solo. Em muitas granjas é comum a aplicação dos dejetos ao solo como forma de fertilização, porém, sem nenhum controle sobre a qualidade do efluente que está sendo lançado. O Ascaris suum é um parasita de suínos que pode infectar humanos, porém não é dada a devida importância à presença deste como contaminante do solo e água. Neste trabalho o efluente de uma suinocultura foi tratado em um sistema composto por reator anaeróbio compartimentado (RAC) e um reator anaeróbio de manta de lodo UASB seguido de lagoas de polimento para remoção de ovos de helmintos. O experimento foi realizado na suinocultura da Fazenda Experimental hélio Barbosa em Igarapé/MG. No afluente foi encontrado valores de ovos de helmintos na faixa de 2.891 a 88.848 ovos $\mathrm{L}^{-1}$, enquanto o efluente apresentou ausência de ovos, mostrando a alta eficiência do sistema de tratamento. Quanto ao lodo das lagoas, este apresentou elevada concentração de ovos viáveis variando entre $10,1 \%$ a $59,8 \%$, fora dos padrões preconizados para a sua utilização na agricultura.
\end{abstract}

Palavras-chave: Contaminação, reuso agrícola, ovos de helmintos

\begin{abstract}
The swine confinement farms and the improper disposal of their wastes carry result in contamination of water and soil. On many farms is common slurry application to soil as a means of fertilization, but without any control over the quality of the effluent being released. What is a parasite Ascaris suum from pigs can infect humans, but is not given due importance to the presence of this contaminant as soil and water. In this work the effluent of a pig was treated in a system composed of anaerobic baffled reactor (ABR) and a UASB followed by polishing ponds for removal of helminthes eggs. The experiment was conducted at the Hélio Barbosa Experimental Farm pig in the city of Igarapé / MG. Values found in the influent of helminthes eggs in the range from 2891 to 88,848 eggs L-1, while the effluent showed absence of eggs, showing the high efficiency of the treatment system. While the sludge ponds, it showed high concentration of viable eggs ranged from $10.1 \%$ to $59.8 \%$, not being in conformity with the requirements for reuse in agriculture.
\end{abstract}

Key words: Contamination, agricultural reuse, helminthes eggs

\footnotetext{
${ }^{1}$ Pesquisadores da Universidade Federal de Minas Gerais, UFMG, BH. E-mail: anasaneamento@gmail.com; drizerbine@yahoo. com.br

${ }^{2}$ Profs. da UFMG, Belo Horizonte, BH. E-mail: 1santosrodrigues@gmail.com; israelvp@gmail.com

${ }^{3}$ Discente da UFMG, Belo Horizonte, BH. E-mail: ludmilabio@ufmg.br

* Autor para correspondência
} 


\section{Introdução}

Muitos patógenos podem sobreviver no solo tempo suficiente para contaminar pessoas e animais, sendo os ovos de helmintos os mais resistentes no ambiente, podendo sobreviver por vários anos no meio ambiente (WHO, 2008).

O Ascaris suum é responsável por uma verminose que acometem suínos levando a significante prejuízo econômico pela redução na eficiência de conversão alimentar e a condenação de vísceras pela migração do parasita durante a fase larvar. Os ovos do $A$. suum são indistinguíveis dos ovos de $A$. lumbricoides, sendo geralmente diferenciados pelas características morfológicas dos vermes adultos. Apesar de ser um parasita específico de suínos pode haver infecção cruzada em humanos. Alguns estudos têm levantado a hipótese do A. suum e do A. lumbricoides serem a mesma espécie (LOREILLE; BOUCHET, 2003; LELES et al., 2012).

A remoção de ovos de helmintos em reatores anaeróbios de manta de lodo UASB ocorre devido à filtração e agregação dos grânulos biológicos na manta de lodo (METCALF; EDDY, 1991). Já nas lagoas de estabilização esta remoção se deve à adsorção em flocos ou ao mecanismo de sedimentação (CAVALCANTI et al., 2001).

A remoção de ovos de helmintos nas lagoas de polimento tem se mostrado eficiente, de forma similar às lagoas de maturação, devendo gerar efluentes com médias aritméticas inferiores a 1 ovo de helminto por litro e, na maioria das amostras, concentrações nulas (SPERLING, 2002). Lagoas de polimento construídas para remoção de coliformes em esgotos urbanos, provavelmente produzem efluente final com concentração de ovos de helmintos de acordo com o recomendado pelo OMS $\left(\leq 1\right.$ ovo L $\left.^{-1}\right)($ SPERLING, 2005).

Em lagoas de estabilização pode ocorrer grande remoção de ovos de helmintos por sedimentação, por isso, todos os fatores que afetam o processo de sedimentação discreta, também afetam a eficiência de remoção de ovos (WHO, 2008).
A Organização Mundial da Saúde (WHO, 2008) sugere que o tempo de detenção hidráulica, em série de lagoas, suficiente para produzir efluentes com menos de 1 ovo $\mathrm{L}^{-1}$ em média, é de 8 a 10 dias. Essa mesma organização estabeleceu também em 2008, para uso de esgotos tratados em irrigação de culturas, o mesmo nível de proteção instituído para água potável, isto é, a carga adicional de doenças causadas pelo consumo de alimentos produzidos pela irrigação com esgotos tratados não deve exceder 10-6 AVAD (Anos de Vida Ajustados em Desabilidade) por pessoa e por ano.

O Programa de Pesquisa em Saneamento Básico (PROSAB), realizou estudos levando em consideração os parâmetros da OMS, conseguindo chegar a diretrizes condizentes com a realidade brasileira para o reúso de esgotos sanitários na área agrícola e na piscicultura, sendo essas sugestões limitadas a critérios de proteção à saúde. Para chegar a esses critérios, Bastos e Bevilacqua (2006) citam que em efluentes de sistemas com tratamento por lagoas a remoção de cistos de protozoários é indicada pela remoção de ovos de helmintos.

Com relação ao reúso do lodo proveniente do sistema de tratamento na agricultura, o Conselho Nacional do Meio Ambiente (CONAMA) estabeleceu critérios e procedimentos para o uso do lodo em áreas agrícolas mediante a publicação da Resolução $n^{0}$ 375/06. De acordo com esta resolução devem ser observados os parâmetros orgânicos, inorgânicos, agentes patogênicos e indicadores microbiológicos, como coliformes termotolerantes, ovos viáveis de helmintos, Salmonella e vírus.

Pode-se observar que vários estudos são realizados sobre remoção de ovos de Ascaris em esgotos urbanos, mas quase nada foi realizado especificamente em efluentes de suinocultura, e observando a possibilidade do A. suum poder ser classificado como zoonose é importante que se comece a estabelecer parâmetros para esse agente, haja vista as diferenças nas características deste tipo de água residuária em função da presença de 
elevada carga orgânica, o que pode interferir na forma de remoção destes patógenos.

Esse trabalho teve como objetivo analisar a remoção de ovos de $A$. suum em um sistema de tratamento de efluentes de suinocultura com reatores anaeróbios (RAC-UASB) seguidos de lagoas de polimento com diferentes profundidades e analisar a presença desses agentes no lodo das lagoas objetivando a sua utilização.

\section{Material e Métodos}

O trabalho foi realizado nas instalações da suinocultura da Fazenda Experimental da Escola de Veterinária da Universidade Federal de Minas Gerais (UFMG), localizada no município de Igarapé, Minas Gerais.

A estação de tratamento de efluentes é constituída de peneira estática, seguida de um reator anaeróbio compartimentado (RAC) seguido de um reator UASB, e tratamento terciário, formado por lagoa facultativa (LF), e por três lagoas de maturação (LM).

O experimento foi dividido em três etapas, sendo que em cada etapa foram testadas três diferentes profundidades na série de lagoas de maturação, como é descrito na Tabela 1.

Tabela 1. Fases do experimento, profundidade das lagoas de maturação (LM), tempo de detenção hidráulico (TDH), período e número de coletas do afluente e efluentes dos reatores anaeróbios e série de lagoas na remoção de ovos de helmintos em efluentes de suinocultura, Igarapé/MG, 2011.

\begin{tabular}{ccccc}
\hline Fase & $\begin{array}{c}\text { Profundidade das LM } \\
(\mathbf{m})\end{array}$ & $\begin{array}{c}\text { TDH } \\
(\text { dias })\end{array}$ & Período & $\mathbf{N}^{\circ}$ de coletas \\
\hline 1 & 0,40 & 5,66 & $23 / 02 / 2010$ a $31 / 08 / 2010$ & 7 \\
2 & 0,60 & 9,93 & $28 / 09 / 2010$ a $28 / 02 / 2011$ & 12 \\
3 & 0,80 & 14,09 & $12 / 12 / 2011$ a $29 / 02 / 2012$ & 12 \\
\hline
\end{tabular}

Fonte: Elaboração dos autores.

Foram coletadas e analisadas amostras do efluente do reator compartimentado, reator UASB, lagoa facultativa e lagoas de maturação, para análise de ovos de helmintos. Os frascos de coleta foram devidamente identificado e transportados para o Laboratório de Saneamento da EV-UFMG sob refrigeração a $4^{\circ} \mathrm{C}$.

Também foram coletadas amostras de lodo da lagoa facultativa e das lagoas de maturação no final do experimento para quantificação e análise de viabilidade dos ovos de helmintos. A metodologia utilizada para detecção e enumeração de ovos de helmintos foi realizada de acordo com a metodologia de BAILENGER modificada por Ayres e Mara (1996), que consiste na concentração das partículas em suspensão por meio de sedimentação com auxílio de centrífuga e posterior flutuação dos ovos com a adição de solução de sulfato de zinco a 33\% para possibilitar a flutuação das estruturas parasitárias. As amostras foram analisadas qualitativa e quantitativamente por meio da observação em câmara de Sedgwick-Rafter no microscópio óptico comum. A análise qualitativa foi realizada pela identificação dos ovos de helmintos encontrados, de acordo com o formato e o tamanho e com o auxílio de Atlas de Parasitologia e chaves de classificação segundo a orientação da OMS (1992).

A identificação dos ovos de helmintos foi baseada, principalmente, no tamanho e na identificação de características morfológicas específicas dos ovos, tais como: forma, conteúdo do ovo, espessura da membrana externa (casca) etc, conforme critérios para identificação dos ovos de helmintos (STOTT, 1998). 
A metodologia para recuperação de ovos de helmintos no lodo foi realizada segundo Meyer, Miller e Kaneshiro (1978). Foi utilizada a equação 1, para o cálculo no número de ovos de helmintos nas amostras.

$$
\mathrm{N}=(\mathrm{A} * \mathrm{X}) / \mathrm{P} * \mathrm{~V}
$$

$\mathrm{N}=$ número de ovos ( $\mathrm{n}^{\circ}$ de ovos por litro);

A: número médio de ovos contados nas câmaras de McMaster (no de ovos)
$\mathrm{X}$ : volume do produto final $(\mathrm{mL})$

P: volume da câmara de McMaster (para câmara de dois retículos $\mathrm{P}=0,30 \mathrm{~mL}$; para câmara de um retículo $\mathrm{P}=0,15 \mathrm{~mL}$ )

$\mathrm{V}$ : volume original da amostra

Os resultados das análises de ovos estão apresentados na Tabela 2, no qual foram realizados estatisitica descritiva.

Tabela 2. Concentração média e desvio padrão de ovos de helmintos do afluente e dos efluentes dos reatores anaeróbios, lagoa facultativa (LF) e efluente final das lagoas de maturação (LM), das fases 1, 2 e 3, Igarapé/MG, 2011.

\begin{tabular}{|c|c|c|c|c|c|}
\hline Parâmetro & Fase & Afluente & Sist. anaeróbio & $\mathbf{L F}$ & $\mathbf{L M}$ \\
\hline \multirow{3}{*}{$\begin{array}{l}\text { Ovos de helmintos } \\
\quad\left(\text { ovos } \mathrm{L}^{-1}\right)\end{array}$} & 1 & $7.825 \pm 4.687$ & $646+275$ & $8+5$ & $0+0$ \\
\hline & 2 & $88.848 \pm 116.520$ & $7.141 \pm 16.699$ & $31+43$ & $0 \pm 0$ \\
\hline & 3 & $2.891 \pm \overline{6} .115$ & $87 \pm 130$ & $3 \pm 4$ & $0 \pm 0$ \\
\hline
\end{tabular}

Fonte: Elaboração dos autores.

\section{Resultados e Discussão}

Na Tabela 2 está apresentada a estatística descritiva com média aritmética dos ovos de helmintos encontrados no afluente e efluente do sistema anaeróbio, LF e LM3.

Santos et al. (2012) avaliando ovos de helmintos em efluentes de duas ETEs em Piracicaba, no estado de São Paulo, encontrou três diferentes ovos de helmintos: Ascaris spp, Taenia spp e Toxocara spp. O número médio de ovos de helmintos observado foi de 3,74 ovos/L de esgoto tratado. Toxocara spp foi a espécie mais encontrada com 3,08 ovos/L, representando uma frequência de $82 \%$ do total encontrado. O valor médio de ovos de Ascaris spp foi de 0,61 ovos/L, sendo 0,35 ovos/L referente a ovos viáveis e 0,26 ovos/L, aos ovos inviáveis, respondendo, em conjunto, por $16 \%$ da frequência total. Os ovos de Taenia spp encontrados apresentaram uma média de 0,05 ovos/L e frequência de $1 \%$

As concentrações de ovos no afluente se encontraram elevadas, com valores de 7825, $88848 \mathrm{e}$ 2891 ovos/L, nas fases 1, 2 e 3 . O sistema anaeróbio apresentou uma boa eficiência de remoção (Tabela 3 ), sendo que parte deve ter ocorrido no RAC por meio da sedimentação. O reator UASB apresentou velocidades ascensionais de 0,39, 0,42 e 0,42 m/h nas fases 1,2 e 3, respectivamente, sendo estes valores baixos, o que provavelmente contribuiu na remoção dos ovos, mesmo com a alta produção de gases que devido sua ascensão no reator poderiam interferir na sedimentação dos ovos. No efluente das lagoas de maturação, não foram encontrados ovos de qualquer espécie em nenhuma das amostras. 
Tabela 3. Eficiências de remoção e unidades logarítmicas removidas (UL) de ovos de A. suum do sistema de tratamento durante as fases do experimento.

\begin{tabular}{cccccc}
\hline Fase & & Sist. anaeróbio & LF & LM & Sistema \\
\hline 1 & Eficiência (\%) & 91,74 & 98,76 & 100 & 100 \\
& UL & 1,08 & 1,91 & & 100 \\
\hline 2 & Eficiência (\%) & 91,96 & 99,57 & 100 & 100 \\
& UL & 1,09 & 2,36 & & 100 \\
\hline 3 & Eficiência (\%) & 96,99 & 96,55 & & \\
& UL & 1,52 & 1,46 & & \\
\hline
\end{tabular}

Fonte: Elaboração dos autores

A WHO (2006) sugere para uma série de lagoas, um período de 8 a 10 dias de tempo de detenção hidráulica seja suficiente para o cumprimento de suas diretrizes para irrigação $\left(\leq 1\right.$ ovo $\mathrm{L}^{-1}$ de efluente tratado) e preconiza também a remoção dos demais organismos patogênicos sedimentáveis. Neste trabalho, uma única lagoa com tempo de detenção hidráulico (TDH) variando entre 23 e 38 dias não conseguiu remover todos os ovos, sendo necessária a série de lagoas de maturação com $\mathrm{TDH}$ total variando entre 5,66 a 14,09 dias para produzir um efluente livre de ovos.

De acordo com Sperling (2002), trabalhos realizados em lagoas piloto de efluentes urbanos no Nordeste e Sudeste do Brasil, conseguiram remoções totais de ovos de helmintos operando com taxas de aplicação hidráulica (TAH) entre 0,12 e $0,20 \mathrm{~m}^{3} / \mathrm{m}^{2}$. d. Neste trabalho a TAH das lagoas de maturação variaram entre 0,21 a $0,32 \mathrm{~m}^{3} / \mathrm{m}^{2}$.d, obtendo os mesmos resultados.

A Tabela 4 apresenta as eficiências médias das lagoas observadas na remoção de ovos de helmintos e as estimadas, segundo a equação de Ayres et al. (1992). A eficiência média estimada da LF foi superior à observada, visto que esta equação foi feita para efluente urbano que apresenta quantidade de ovos bem inferior à encontrada neste trabalho. No efluente final das lagoas de maturação, a eficiência observada foi maior, provavelmente pelo baixo TDH das lagoas de maturação, fundamental para o cálculo da eficiência estimada. Cavalcante et al. (2010), pesquisando esgoto urbano tratado por filtros anaeróbios, relataram eficiência de remoção de ovos de helmintos de $99,5 \%$.

Tabela 4. Eficiências observadas e estimadas segundo Ayres et al. (1992) do afluente e efluentes dos reatores anaeróbios e série de lagoas na remoção de ovos de helmintos em efluentes de suinocultura, Igarapé/MG, 20011.

\begin{tabular}{ccccc}
\hline Fase & $\begin{array}{c}\text { Eficiência de } \\
\text { remoção (\%) }\end{array}$ & LF & LM & $\begin{array}{c}\text { Sistema de } \\
\text { lagoas }\end{array}$ \\
\hline 1 & Observada & 98,76 & 100 & 100 \\
& Estimada & 99,998 & 98,91 & 99,9998 \\
\hline 2 & Observada & 99,57 & 100 & 100 \\
& Estimada & 99,9997 & 99,68 & 99,9999 \\
\hline 3 & Observada & 96,55 & 100 & 100 \\
& Estimada & 99,9997 & 99,93 & 99,9999 \\
\hline
\end{tabular}

$\mathrm{LF}$ = lagoa facultativa; $\mathrm{LM}=$ lagoa de maturação

Fonte: Elaboração dos autores. 
Para verificar a qualidade higiênica do lodo acumulado no fundo das lagoas durante o período experimental, foi analisada a viabilidade dos ovos de $A$. suum incorporados ao lodo. Na Tabela 5 pode- se verificar o número de ovos encontrados no lodo em cada ponto de coleta das lagoas de tratamento, além do número e porcentagem dos ovos viáveis.

Tabela 5. Quantidades e médias de ovos de A. suum no lodo, ovos viáveis e porcentagem de viabilidade nas lagoas de tratamento.

\begin{tabular}{|c|c|c|c|}
\hline Pontos & $\mathrm{N}^{\mathbf{0}}$ de ovos $\mathrm{g}^{-1} \mathrm{MS}$ & $\mathrm{N}^{\mathbf{0}}$ ovos viáveis $\mathrm{g}^{-1} \mathrm{MS}$ & $\%$ ovos viáveis $\mathrm{g}^{-1} \mathrm{MS}$ \\
\hline LF1 & 8225 & 433 & 5,3 \\
\hline LF2 & 6633 & 603 & 9,1 \\
\hline LF3 & 3800 & 405 & 10,7 \\
\hline LF4 & 7123 & 1350 & 19,0 \\
\hline LF5 & 2299 & 144 & 6,3 \\
\hline LF6 & 2960 & 217 & 7,3 \\
\hline Média & 5173 & 525 & 10,1 \\
\hline $\mathrm{LM} 1 / 1$ & 3459 & 2013 & 58,2 \\
\hline $\mathrm{LM} 1 / 2$ & 2289 & 1095 & 47,8 \\
\hline Média & 2875 & 1554 & 54,1 \\
\hline LM2/1 & 927 & 143 & 15,4 \\
\hline $\mathrm{LM} 2 / 2$ & 568 & 52 & 9,2 \\
\hline Média & 748 & 98 & 13,1 \\
\hline LM3/1 & 202 & 202 & 100,0 \\
\hline $\mathrm{LM} 3 / 2$ & 136 & 0 & 0 \\
\hline Média & 169 & 101 & 59,8 \\
\hline
\end{tabular}

MS = matéria seca; $\mathrm{LF}=$ lagoa facultativa; $\mathrm{LM}=$ lagoa de maturação

Fonte: Elaboração dos autores.

A LM1 apresentou a maior concentração de ovos viáveis, com 1554 ovos viáveis/g MS (matéria seca), e a LM2 a menor, com 98 ovos viáveis/g MS, porém a LM3 foi a que apresentou a maior porcentagem, com $59,8 \%$. O lodo das lagoas apresentou concentrações de ovos viáveis bem acima das recomendadas pela Resolução no 375/06 do CONAMA para utilização na agricultura, de menos de 0,25 ovos viáveis $\mathrm{g}^{-1}$ ST para classe A e menos de 10 ovos viáveis/g ST para lodo classe $\mathrm{B}$, não atendendo à essas diretrizes. Esse resultado já era esperado em função da grande quantidade de ovos no afluente do sistema, além da alta resistência desse parasita no ambiente.

Com bases nos resultados obtidos podese concluir que as lagoas de maturação foram extremamente eficientes na remoção de ovos de helmintos, não sofreram influência das diferentes profundidades e nem dos baixos tempos de detenção hidráulica. Diferente do relatado em esgoto urbano, taxas de aplicação hidráulica variando entre 0,21 a $0,32 \mathrm{~m}^{3} / \mathrm{m}^{2}$.d não interferiram na eficiência das lagoas. O lodo apresentou elevada concentração de ovos viáveis, inviabilizando o uso na agricultura.

\section{Agradecimentos}

Agradecemos a Fundação de Amparo à Pesquisa do Estado de Minas Gerais (FAPEMIG) pelo financiamento da pesquisa. 


\section{Referências}

AYRES, R. M.; ALABASTER, G. P.; MARA, D. D.; LEE, D. L. A design equation for human intestinal nematode egg removal in waste stabilization ponds. Water Research, Leeds-Inglaterra, v. 26, n. 6, p. 863-865, 1992.

AYRES, R. M.; MARA, D. D. Analysis of wastewater for use in agriculture: a laboratory manual of parasitological and bacteriological techniques. Geneva: World Health Organization, 1996. 35 p.

BASTOS, R. K. X.; BEVILACQUA, P. D. Normas e critérios de qualidade para reúso da água. In: SANTOS, M. L. F.; BASTOS, R. K. X.; AISSE, M. M. (Coord.). Tratamento e utilização de esgotos sanitários. Rio de Janeiro: ABES, 2006. p. 17-62.

CAVAlCANTE, F. L.; ANDRADE NETO, C. O.; ARAÚJO, A. L. C.; MELO, H. N. S. Eficiência sanitária de filtros anaeróbios avaliados em função da remoção de ovos de vermes e coliformes fecais. Revista AIDIS, Lagoa Nova-Brasil, v. 3, n. 1, p. 49-61, 2010.

CAVALCANTI, P. F. F.; VAN HAANDEL, A. C.; KATO, M. T.; SPERLING, M.; LUDUVICE, M. L.; MONTEGGIA, L. O. Pós-tratamento de efluentes anaeróbios em lagoas de polimento. In: CHERNICHARO, C. A. L. (Coord.). Pós-tratamento de efluentes de reatores anaeróbios. Belo Horizonte: PROSAB, 2001. v. 2, p. 105-170. (Coletânea de Trabalhos Técnicos).

LELES, D.; GARDNER, S. L.; REINHARD, K.; IÑIGUES, A.; ARAUJO, A. Are Ascaris lumbricoides and Ascaris suum a single species? Parasites and Vectors, Rio de Janeiro, v. 42, n. 5, p. 2-7, 2012.

LOREILLE, O.; BOUCHET, F. Evolution of ascariasis in humans and pigs: a multi-disciplinary approach. Memórias do Instituto Oswaldo Cruz, Rio de Janeiro, v. 98, 2003. Suplemento 1.
METCALF, L.; EDDY, H. Wastewater engineering: treatment, disposal and reuse. 3. ed. Nova Iorque, NY: McGraw-Hill, 1991. 1334 p.

MEYER, K. B.; MILLER, K. D.; KANESHIRO, E. S. Recovery of Ascaris eggs from sludge. The Journal of Parasitology, v. 64, n. 2, p. 380-383, 1978.

ORGANIZACIÓN MUNDIAL DE LA SALUD - OMS. Métodos básicos de laboratorio en parasitologia medica. OMS: Genebra, 1992.

SANTOS, J. G.; PIVELI, R. P.; CAMPOS, F.; SUNDEFELD, G.; SOUSA, T. S.; CUTOLO, S. A. Análise parasitológica em efluentes de estações de tratamento de águas residuárias. Revista de Patologia Tropical, v. 41, n. 3, p. 319-336, jul./set. 2012.

SPERLING, M. Introdução à qualidade das águas e ao tratamento de esgotos. 3. ed. Belo Horizonte: DESA/ UFMG, 2005. (Princípios do Tratamento Biológico de Águas Residuárias, v. 1).

. Lagoas de estabilização. 2. ed. Belo Horizonte: DESA/UFMG, 2002. (Princípios do Tratamento Biológico de Águas Residuárias, v. 3).

STOTT, R. Enumeration of intestinal helminth ova in raw and treated wastewaters. A training manual. Porstmouth: Department of Civil Engineering, University of Portsmouth, 1998.

WORLD HEALTH ORGANIZATION - WHO. Guidelines for the safe use of wastewater, excreta and greywater. Genebra: [s.n], 2006.

Soil-transmitted helminths. Genebra: [s.n], 2008. Disponível em: <http://www.who.int/intestinal_ worms/en/WHO>. Acesso em: 15 abr. 2012. 
